\title{
Gathering Production Processes of Services and Goods: Towards the Mixed Enterprise
}

\author{
ALIX Thècle, VALLESPIR Bruno \\ LAPS/GRAI University Bordeaux 1 - ENSEIRB - UMR CNRS 5131 \\ 351, cours de la liberation 33405 TALENCE CEDEX FRANCE \\ tel.: +33540006532 fax: +33540006644
}

\begin{abstract}
In 2003, the French government advised manufacturing enterprises to associate service to the product they manufacture in order to keep competitive and profitable. This service orientation represents a huge challenge that impacts organisation, management, and control of industrial firms but also people's focus and skills which must be less technology oriented but rather customer oriented. Here we focus on the organisation required to propose products and services at the same time. In this objective, this paper recalls the differences and similarities between goods and services characteristics, processes and problematic to provide in fine a functional and control grids of an enterprise able to propose to its customers a combined (good+service) offer or a simple one.
\end{abstract}

\section{Introduction}

In 2003, a French governmental report invited manufacturing firms to associate peripheral services to the products they deliver to gain in competitiveness and to be profitable [1]. As SMEs are aligned from a competitive point of view as regard to technologies or know how mastered, a way of positioning manufacturers on durable bases is to direct their offers to meet customers' interests. This means to complement the product oriented added value with a customer oriented added value proposing to their customers offers made up with tangible goods and additional services [2]. The consequences of this new positioning are twofold:

- for manufacturing firms because they are obliged to extend their abilities or to develop alliances with services providers,

- for services providers that are obliged to mass customize their offer to face a new concurrency.

The objective of this paper is to analyze the implications of this trend for manufacturing firms willing to extend their offer internally and then become mixed enterprises. So, after a slight reminder of the characteristics of goods and services,

Please use the following format when citing this chapter:

Alix, T. and Vallespir, B., 2008, in IFIP International Federation for Information Processing, Volume 257, Lean Business Systems and Beyond, Tomasz Koch, ed.; (Boston: Springer), pp. 317-325. 
the paper will detail the production and "servuction" processes to underline the elements that are taken into account in each one separately. The goal is to demonstrate that as goods and services, the processes to create them are neither exclusive and can be combined in a provuction process. The problematic proper to each industry are developed in a fourth part in order to be taken into account during the design study of a mix enterprise. It emerges a functional and control grid of a provuction system that underline the main function to manage in such a case.

\section{Contrast between services and goods characteristics}

Services are most of the time defined in contrast with goods using attributes that do not concern these latest [3], [4]. Even if the delineation is less and less obvious [5], [6], the four main attributes used to characterise services are intangibility, heterogeneity perishability and inseparability.

Intangibility refers to service immateriality. However, since a need of service can results in a set of materials that make it tangible for a physical distribution, or that a set of material respond to a need rendering a service, materials and services can be twin vision of a same object and components of a whole whose dominant is service oriented. In this case, we use the term of 'product' for the couple (material, service) and 'basic service' for the delivered service. Then a service can exist as such (intangible pure service that can not be stored) or supported by a product [7], [8].

The customer implication in pure service delivery system confers to services an attribute of heterogeneity which is mainly explained by the presence of human factor that influences the quality of result and prevents service standardization [9]. However, because an expected result is defined, the human factor only implies a customer particularization, as it exists in manufacturing production. A standard process can be defined that could allow to homogenize pure services.

Another strong characteristic of services is that they are perishable and can not be stored because of their intangibility [10]. This characteristic loses its meaning since basic services are stored in a product and that basic services such as training can be stored in systems, knowledge, persons.... Moreover, if the concept of perishability is associated to the concept of obsolescence, materials are also perishable.

Inseparability constitutes the last strong attribute of the services. It results in the simultaneous contribution of the customer and the producer during service set up. As some parts of the processes are automated because of the search for profitability, service delivery system is more and more disconnected from the customer whose presence is not mandatory since the beginning of the service design. Conversely and even if it implies heavy constraints related to the productivity, customers are more and more implied in the design phase of goods.

As we can see, the four properties above-mentioned do not make possible to radically distinguish goods from services that can have the same attributes under time and space scale constraints. The narrowness of the border between them led to the conclusion that there can be a common base to create them. 


\section{Contrast between services and goods processes}

The service delivery system corresponds to the systematic and coherent organization of all the physical and human elements coming from the customer/enterprise interface that are necessary for service delivery according to predetermined commercial characteristics and quality levels of appreciation [11], (see figure 1). The three elements required to deliver a pure intangible service are the customers, the contact people and the physical support.
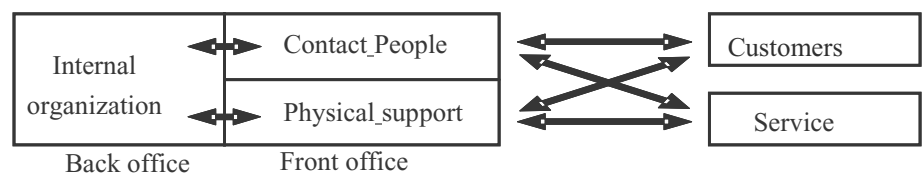

Fig. 1. Service delivery system

The production process integrates all the processes that are necessary for the transformation of materials using technical and human resources (see figure 2). Then the three elements required to deliver goods are technical human resources, technical operative resources and raw materials.

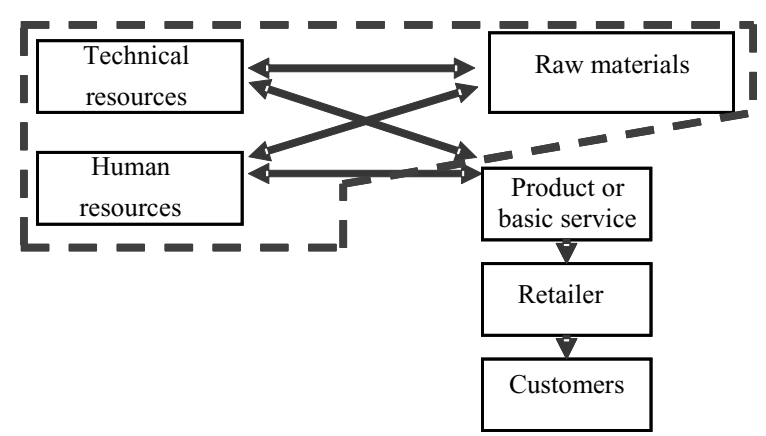

Fig. 2. Production process

The main difference is the place of the customer. Considered as an actor in the service delivery system, he is out of the production process. The justification comes from the idea that the customer is mandatory to define the service he needs and that he creates and consumes the service during the same period of time. However as seen before, a part of the service process can be automated in back office for profitability raisons and personalized to the customer in front office. This way of doing is coherent regarding the current manufacturing process for which the customers can intervene to personalize the product he wants to buy before its end. 
The practical similarities lead us to propose a common provuction process that can be instantiated to the provision of personalized goods and/or services that can be automated for a part of their realization (figure 3).

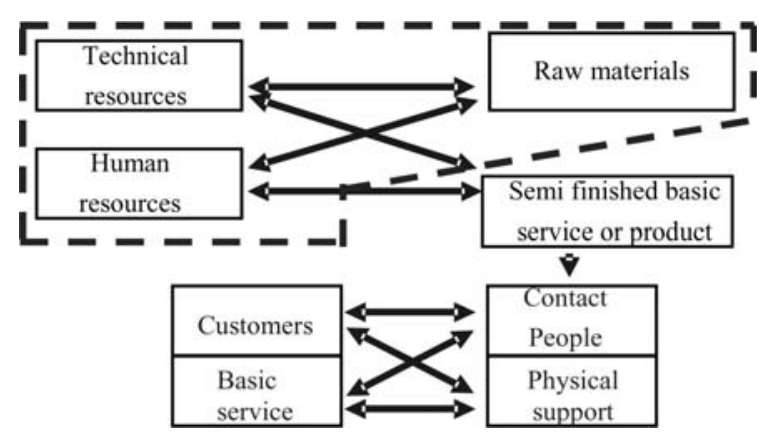

Fig. 3. Provuction process

\section{Contrast between services and goods problematic}

The preoccupations in the service domain and in the production domain are quite different. This implies that the focus is not put on the same things and that even if some issues are common, they can have different meanings according to the context.

\subsection{Preoccupation in the service domain}

Regarding the service delivery system, it is obvious that the main preoccupations will refer to the process by itself, to the customer and to the interrelations between the persons that are in party, to the service result, appreciation and quality, and to the system offer structure [12]. These elements have lead to define some management problematic such as:

- Customer relationship management deals with the development of customer loyalty by a mutual learning relation which is value added, customized and interactive. This implies to study the relation of service i.e. methods of exchange, communication protocols for the before and after sales, consumer behavior of purchase, customer forms of participation ...

- Quality management because since the customer is co producer of the service, the level of quality of a service depends on:

- The different implications and interrelations: customer, contact people, other customers,

- The result of the service,

- The operations fluidity, exchange facilities between individuals.

Contextual and subjective, the customer feelings (influenced by his personal needs, prior experience, environment...) act on its perception of the quality of the service and on its decision of service purchase. 
- Load and capacity management because as service are subject to demand fluctuations, it is then very difficult to anticipate the quantity and the type of service to be returned. A challenge is to determine the right service to provide (sub problematic of quality) to the right customer (sub problematic of customer relationship management) in the right place (sub problematic of (e-)distribution) at the right price (sub problematic of price fixing and by extension of yield management).

\subsection{Preoccupation in the production domain}

Regarding the production domain, the main preoccupations refer to the process management by itself, to the resource management (human or technical), to the product management (raw material, semi finished or finished) and to the synchronization between the products and the resources. Other elements such as distribution, sales... are also managed but the focus depth can be different regarding the enterprise objectives. As in service delivery the customer relationship management and the quality management seems to be key functions of management but have different representation:

- the customer relationship is most of the time only managed before the sales and consists in a marketing action to identify the product to manufacture.

- the quality criterion depend mostly on a functional schedule of conditions, even if an evolution can be noted to take all these elements into account because of competitiveness growth.

\section{Generic model of a mix enterprise}

This part assumes that as a mixed enterprise will propose goods and services, its models must gather the particularities of each output separately. Then, the functional model and control grid proposed are based on the provuction process presented before and on the management functions that can not be bypassed when a good or a service is provided. The formalism used is the GRAI formalism [13].

\subsection{Basic components of the provuction system}

The provuction process presented before permits to define the basic components of the mix enterprise. Are distinguished:

- technical resources: material elements physical support for the transformation activity,

- products which can split up into raw materials (inputs for production process) and semi finished / finished products or services (output of provuction process),

- human resources which can be split into human resources with technical competencies that intervene in back office on the product realisation and human resources with commercial competencies that intervene in front office to personalize the output of the process, 
- the customer: individual recipient of the combined offer.

According to the type of production considered at a given moment, each component will be globally (or not) taken into account to manage the process.

\subsection{Strategic functions to manage}

The latest developments lead us to integrate among the strategic functions to manage: "provuction" management, commercial/marketing and quality management functions. Two others functions need to be taken into account to help deciders to manage a mix enterprise: Finally, service orientation represents a huge challenge that impacts organisation, management, and control of industrial firms but also people's focus and skills which must be less technology oriented but rather customer oriented. distribution management and innovation management functions. Figure 4 represents the functional grid of a provuction system.

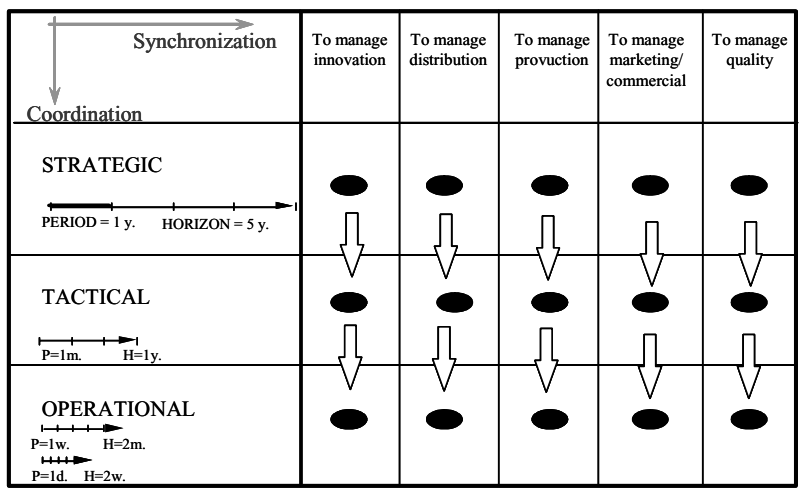

Fig. 4. Functional grid of a provuction system

Provuction function. The "provuction" function gathers the two functions of production and service delivery necessary for the management of the respective processes. The goal of this function is to synchronize the basic components abovementioned. The management of the provuction can be apprehended from a temporal and functional point of view:

- the temporal decomposition allows to define the strategic level (which activity portfolio?), the tactical level (which component organisation as regard to commercial forecasts) and the operational level (which execution modalities for the activities),

- the functional decomposition that implies the management of products, human resources, technical resources and customers. The goal is to ensure the availability of these components per time units, sort of macro planning that needs to be refined at the operational level according to customer availability. A synchronisation function is then necessary to coordinate customers, resources, and products flows. 
Such a classification implies a hierarchy of representations. Each decisional level is characterised by a couple (horizon, period) and by a level of detail of the information taken into account. Figure 5 presents the detail of the provuction control system. It summarizes the decisional structure of the system considered.

Commercial/marketing function. Service costing and price fixing is a problem of huge importance in the domain of service because as they are for a part intangible, their value is influenced by customers feeling of quality ( $\$ 4.1)$. Furthermore, in the particular case of activities diversification such as it is for manufacturing firm, studies have shown that whatever the type of service, only $31 \%$ of firms sell them [14]. A strategic plan must be held to determine the best coupling (product/service) taking account of the marketing and commercial strategy that lies on the global strategy of the firm. Then the marketing function must define the global offer and fix its price taking account of the service and product process cost and of the customer perception of the offer value. At a tactical and operational level, the function will have to manage customers thanks to a relational approach and to set up loyalty programs. The commercial function must determine on the long term how to maximize the profits of the firm optimizing on the medium and short term the resource utilisation regarding their capacity.

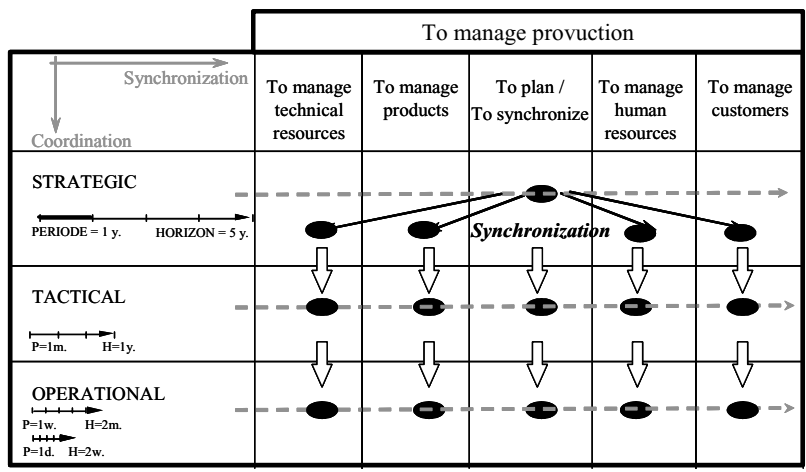

Fig. 5. Control grid of the provuction system

Quality function. Quality is the main loyalty indicator, the main asset considering the concurrency and the essential axis to ensure the growth and profitability of firms. As a consequence it must be manage at each decisional level. A problem comes from the difficulty to define quantitative metrics representative of the service quality and productivity [15]. At a strategic level, procedures to check process quality should be defined and at the operational level metrics can be used to demonstrate the quality of the tangible part of the offer whereas measures that will solicit customers or contact people could be defined for the other part.

Innovation function. Innovation recovers all the creative processes that are used to enhance or introduce new goods, services or processes in firms. Tool for 
differentiation its articulation regarding the global strategy of the firm and the commercial/marketing strategy will allow to anticipate the further developments of firms, investments in term of technical or human resources and technologies or competencies to master.

Distribution function. Service delivery or good provision requires to determine when, where and how to distribute. The TIC widespread in the service domain imply that the commercial/marketing strategy of the mix enterprise takes time and space parameters into account and focus on physic and electronic delivery. A strong correlation exists between the information system, the customer relationship and the distribution functions that need to be managed on the short, medium and long term.

\section{Conclusion}

The economic delineation that exists between goods and services looses its interest regarding the provision of a combined offer and the set up of processes to perform it. Then, erasing the existing border between goods and services, we have proposed a provuction process that allows providing personalised goods as well as standardized services. The decisional structure of an enterprise able to propose such an offer and to support such a process is also presented. In order to define the complete model of such a firm, the physical and information models should be studied and the decisional model improved.

\section{References}

1. Lagaronne C., Ramus V., Gallardo E., et Zaeh F. Orientation service Entreprises : renforcez votre offre industrielle avec du service, note de synthèse rédigée pour le Ministère de L'Economie des Finances et de l'Industrie, 2003.

2. Malleret V. La rentabilité des services dans les entreprises industrielles : enquête sur un postulat, Cahier de recherche Groupe HEC, 2005.

3. Rathmell J.M. What is meant by services, Journal of marketing, October, 1986.

4. Gummesson E. Evert Gummesson : Stockholm University, in services marketing self-portraits : introspections, reflections and glimpses from the experts, 2000.

5. Judd R.C. The case for redifining services, Journal of marketing, 28(1), 1964.

6. Vargo S.L., and Lusch R.L. Evolving of a new dominant logic for marketing, Journal of Marketing, 68 (january),2004.

7. Gronroos C. Service management and marketing: a customer relationship management approach, West Sussex, UK :Wiley, 2000. 
8. Alix T., Vallespir B. Product and complementary service: looking for the right pair, Proceedding of the IEEE SSMC conference, Troyes, 2006.

9. Malaval P. L'essentiel du marketing B to B, Editions Publi-Union, Paris, 1999.

10. Vargo S.L., and Lusch R.L. The four service marketing myths: remants of a good-based manufacturing model, Journal of Service Research, 6(4), 2004.

11. Eiglier P., Langeard E. Servuction, le marketing des services, Mc Graw Hill, Paris, 1987.

12. Tannery F. Le management stratégique des services : synthèse bibliographique et repérage des questions génériques, Finance Contrôle Stratégie, 4(2), 2000.

13. Doumeingts G., Vallespir B. and Chen D. Decisional modeling GRAI grid in International Handbook on Information Systems, eds Springer, Berlin, 1988.

14. Baglin G., Malleret V. Le développement d'offres de services dans les PMI", cahier de recherche du Groupe HEC, CR 800/2004.

15. Norman R. and Ramirez R. From value chain to value constellation: designing interactive strategy, Harvard Business review, 71, july-august, 1993. 